This study was designated to evaluate the influence of behavioral depression on the airway leukocyte recruitment in allergic animals. To achieve this, total and differential cell counts in bronchoalveolar (BAL) fluid of ovalbumin (OVA)-sensitized and depressed rats was evaluated. Inescapable electric footshock, applied on day 0,7 and 13 after OVA sensitization, was used as a model to induce depression. In both nondepressed and depressed groups, the number of total and differential cells (eosinophils and mononuclear cells) in BAL fluid was significantly larger in sensitized compared with non-sensitized animals. However, no statistical differences were found between these groups with respect to the number of total and differential leukocytes, irres pective of the day inescapable shock was applied. Thus, behavioral depression does not influence the pattern of cell infiltration into the airways of allergen-induced airway inflammation.

Key words: Acute stress, Eosinophils, Allergic asthma, Inflammation, Lungs

\section{Evidence that behavioral depression does not influence airway cell influx in allergic rats}

\author{
Marcos A. Varriano, Ana A. Varriano, Fernanda Datti, \\ Marcelo Datti, Edson Antunes and \\ Nancy A. Teixeira ${ }^{\text {CA }}$
}

Department of Pharmacology, Faculty of Medical Sciences, UNICAMP, P.O. Box 6111, 13081-970

Campinas (SP), Brazil

\author{
${ }^{\mathrm{CA}}$ Corresponding author \\ Tel: +551937887185 \\ Fax: +551932892968 \\ E-mail: airoldi@obelix.unicamp.br
}

\section{Introduction}

Asthma is one of the most common chronic pulmonary diseases. It is characterized by bronchial hyperresponsiveness and airway inflammation, both of which result in obstruction of the breathing tubes. Besides edema of the mucous membrane, enhanced production of mucus, damage of mucociliary movement and epithelium, a marked accumulation of leukocytes, particularly eosinophils and lymphocytes, is observed in the airways, where they are believed to play a key role in the pathogenesis of asthma. ${ }^{1}$ Correlations between the eosinophil number and the severity of this disease have also been observed. ${ }^{2}$

Asthma-like airway inflammation is achieved in rats by subcutaneous injection of ovalbumin (OVA), which leads to an increased production of $\mathrm{IgE}$ antibodies for this allergen. Thus, in OVA-sensitized animals, challenge with this allergen evokes an initial recruitment of neutrophils followed by a delayed eosinophil influx, as detected in both the bronchoalveolar lavage (BAL) fluid and lung tissues. ${ }^{3,4}$ Using this model, we recently showed that chronic mild unpredictable prenatal stress produces a marked increase in the allergen-induced airway inflammation in the rat offspring, as evaluated by the large recruitment of eosinophils into their airways. ${ }^{5}$ Studies carried out in humans and experimental animals have also suggested that emotional acute stress can contribute to the onset or severity of allergic asthma, particularly in association with behavioral depression. ${ }^{6-11}$ Since no studies have focused on the effects of behavioral depression on the airway leukocyte recruitment in allergic animals, we designed experiments to evaluate the total and differential (neutrophils, eosinophils and mononuclear cells) leukocyte counts in BAL fluid of OVA-sensitized and depressed rats.

\section{Materials and methods}

\section{Animals}

Adult female Wistar rats (3-5 months old) provided by the Biology Institute Laboratory Animal Center (CEMIB) of the State University of Campinas (UNICAMP) were used. They were grouped in propylene cages with metal rung tops, with free access to water and food. The light cycle was automatically controlled (on 6:00 a.m./off 6:00 p.m.), and the room temperature was thermostatically regulated to maintain $26 \pm 2^{\circ} \mathrm{C}$. Rats were housed in individual cages 3 days before the experiment. All experiments were carried out in accordance with the guidelines of UNICAMP.

\section{Behavioral depression model}

In this study, the inescapable electric footshock was used as a model to induce behavioral depression in rats, as previously described. ${ }^{12}$ Briefly, the shock box consisted of a plexiglass box $\left(25 \times 19.5 \times 19.5 \mathrm{~cm}^{3}\right)$ equipped with a grid floor having stainless steel bars, where inescapable $1.0 \mathrm{~mA}$ footshocks were delivered. 
The footshocks were generated by a shock generator (Albarsch, PortoAlegre, Brazil) connected to the shock box and to a microcomputer (XT 2002; Microtec, Porto Alegre, Brazil) executing a software program described by Hermini et al. ${ }^{13}$ This program controlled the shock on/off periods and was based on the escape latencies of 199 animals determined during a series of 60 footshocks delivered over $30 \mathrm{sec}$ in a shuttle box. The duration of the shocks varied from 0.58 to $18.18 \mathrm{sec}$, and each shock was separated by an interval of 5-25 sec. One rat per session was placed in the shock box and after $1 \mathrm{~min}$ of adaptation they were exposed to 60 inescapable scrambled electric footshocks of 1.0 mA each. Non-depressed rats were only maintained in the shock box and used as controls. This procedure leads to an escape deficit, observed exclusively in inescapably shocked animals when exposed to a session of escapable shocks, $24 \mathrm{~h}$ later. Such behavioral deficit, extensively described in literature, is considered an animal model of depression. ${ }^{14}$

\section{Sensitization procedure and antigen challenge}

Rats were sensitized against OVA chicken egg (Grade III; Sigma, St. Louis, MO, USA). Active sensitization was performed by subcutaneous injection of $0.15 \mathrm{ml}$ of solution containing $200 \mu \mathrm{g}$ of OVA and $8 \mathrm{mg}$ of $\mathrm{Al}(\mathrm{OH})_{3}$, prepared in saline according to a previous study, ${ }^{3}$ with slight modifications. Non-sensitized rats received only $8 \mathrm{mg}$ of $\mathrm{Al}(\mathrm{OH})_{3}$. On day 14 , both sensitized and non-sensitized rats were anaesthetized with chloral hydrate $(300 \mathrm{mg} / \mathrm{kg}$, intraperitoneally (i.p.)) and the trachea was exposed through a midline ventral incision of approximately $0.5 \mathrm{~cm}$ length in the neck. With the aid of a 26.5 gauge needle, $0.4 \mathrm{ml}$ of $0.25 \%$ solution of OVA was injected into the airways. Immediately after this procedure, the animals were sutured and allowed to recover from the anesthesia.

\section{Leukocyte number in bronchoalveolar lavage}

BAL fluid was performed $48 \mathrm{~h}$ after OVA challenge. Briefly, the animals were again anaesthetized with chloral hydrate (300 mg/kg, i.p.) and exsanguinated by aortic puncture. The trachea was exposed and cannulated with a polyethylene tube (1 mm diameter) connected to a syringe. The lungs were washed by flushing with phosphate-buffered saline (PBS) solution containing heparin $(20 \mathrm{IU} / \mathrm{ml})$ and $0.03 \%$ serum albumin. The PBS buffer was instilled through the tracheal cannula as one $10 \mathrm{ml}$ aliquot followed by three $5 \mathrm{ml}$ aliquots. The BAL recovered after each aliquot instillation was combined and centrifuged at $1000 \times g$ for $10 \mathrm{~min}$ in a Hermle centrifuge $(\mathrm{Z} 360 \mathrm{~K}$, Berthold Hermle AG, Gosheim, Germany). The cell supernatant was discarded and the cell pellet was resuspended in $2 \mathrm{ml}$ of PBS buffer. The total cell numbers were counted in Türk's solution while differential counts were carried out on air-dried smears stained with MayGrunwald-Giemsa. A minimum of 300 cells was counted in optic microscope and classified as neutrophils, eosinophils and mononuclear cells based on normal morphological criteria.

\section{Experimental procedure}

The afore-described protocols resulted in four experimental groups (seven to eight rats each): (1) nondepressed, non-sensitized; (2) non-depressed, sensitized; (3) depressed, non-sensitized; and (4) depressed, sensitized. The inescapable electric footshock was applied in three different time intervals after OVA sensitization: day 0 , day 7 or day 13 , considering day 1 as the day of sensitization.

\section{Statistical analysis}

All data are expressed as mean and SEM. Data were analyzed with the use of analysis of variance followed by the Turkey-Kramer test for multiple comparisons. $p$ $<0.05$ was considered to indicate significance.

\section{Results}

Total and differential leukocyte counts in bronchoalveolar lavage (BAL) fluid

In the non-depressed group, the content of total leukocytes in BAL fluid in response to intratracheal injection of OVA was significantly larger $(p<0.05)$ in OVA-sensitized ( $48 \mathrm{~h})$ compared with non-sensitized animals, as expected (Table 1). This was associated with marked influxes of eosinophils (ranging from 35 to $50 \%$ ) and mononuclear cells (ranging from 42 to $58 \%$ ). Similarly, in the depressed group, the intratracheal injection of OVA caused a higher cell influx in sensitized rats compared with non-sensitized animals, irrespective of the day of application of the inescapable shock. However, no statistical differences in the total cell counts of OVA-sensitized rats were found between depressed and non-depressed groups (Table 1 ).

In the non-depressed group, a significant $(p<0.05)$ eosinophil recruitment in BAL fluid was observed in sensitized rats, as compared with the non-sensitized animals (Fig. 1A). A similar result was observed in the depressed group when both non-sensitized and sensitized animals were compared. However, no statistical differences in sensitized animals where observed between depressed and non-depressed groups, irrespective of the day of application of the inescapable shock (Fig. 1A).

In the non-depressed group, the number of mononuclear cells in BAL fluid from OVA-sensitized rats was significantly higher than from non-sensitized rats (Fig. 1B). Similarly, in the depressed group, the mononuclear cell counts were significantly higher in OVA-sensitized rats compared with non-sensitized rats; except at day 0 , 
Table 1. Total leukocyte counts in BAL fluid from both non-depressed (non-sensitized and sensitized) and depressed (nonsensitized and sensitized) rats in response to intratracheal injection of OVA $(0.4 \mathrm{ml}$ of $0.25 \%$ ovalbumin solution)

\begin{tabular}{|c|c|c|c|c|}
\hline & \multicolumn{4}{|c|}{ Leucocyte number $\left(\times 10^{6} / \mathrm{BAL}\right)$} \\
\hline & \multicolumn{2}{|c|}{ Non-depressed } & \multicolumn{2}{|c|}{ Depressed } \\
\hline & Non-sensitized & OVA-sensitized & Non-sensitized & OVA-sensitized \\
\hline Day 0 & $3.2 \pm 0.6$ & $10.1 \pm 1.6^{*}$ & $4.1 \pm 0.5$ & $9.9 \pm 1.6^{*}$ \\
\hline Day 7 & $2.2 \pm 0.3$ & $7.5 \pm 2.8^{*}$ & $2.4 \pm 0.4$ & $6.5 \pm 0.6^{*}$ \\
\hline Day 13 & $2.8 \pm 0.2$ & $11.0 \pm 2.2^{*}$ & $3.2 \pm 0.6$ & $16.3 \pm 3.8^{*}$ \\
\hline
\end{tabular}

BAL fluid was evaluated at $48 \mathrm{~h}$ post-OVA injection. ${ }^{*} p<0.05$ compared with respective non-sensitized groups. Results are mean values \pm SEM of data from seven or eight rats.

where no statistical differences between non-sensitized and sensitized rats were observed (Fig. 1B). When the mononuclear cell counts in sensitized rats in both the non-depressed and depressed groups were compared, no statistical differences were found.

FIG. 1. Effects of inescapable shock applied on day 0 , day 7 or day 13 on the eosinophil (A) and mononuclear cell (B) counts in BAL fluid after $48 \mathrm{~h}$ following intratracheal injection of OVA. Each column represents the mean \pm SEM $(n=7-8)$. ${ }^{*} p$ $<0.05$ compared with respective non-sensitized groups. NDNS, Non-depressed, non-sensitized; ND-S, non-depressed, sensitized; D-NS, depressed, non-sensitized; D-S, depressed, sensitized.
The neutrophil counts in BAL fluid of OVA-sensitized rats were low both in the non-depressed (2-13\%) or depressed (2-12\%) groups, irrespective of the day of application of inescapable shock (not shown).

\section{Discussion}

The present study clearly demonstrates that behavioral depression does not change the pattern of total and differential leukocyte infiltration into the airways of allergen-induced airway inflammation in rats, irrespective of the day of application of inescapable electric footshocks before ovalbumin challenge (1, 7 or 15 days).

Accumulation of eosinophils cells into tissues is a feature of a variety of allergic diseases, including asthma. ${ }^{15}$ The sequence of molecular events that lead mature eosinophils to mobilize from bone marrow to peripheral blood and to airways are poorly understood, but it is well established that these events are modulated by certain cytokines, including interleukin-5 and eotaxin, and by the adhesion molecules VLA-4 and VCAM-1. ${ }^{16}$ Our findings that inescapable electric footshocks had no effect on the pattern of eosinophil infiltration in BAL fluid of allergen-sensitized rats rule out that behavioral depression affects mechanisms that contribute to lung eosinophil migration in allergic rats. A similar conclusion could be drawn with respect to mononuclear cell counts in OVA-sensitized rats, where the inescapable electric footshocks failed to affect the counts of these cells in BAL fluid. Interestingly, chronic mild unpredictable prenatal stress has been shown to increase the number of eosinophils in BAL fluid of offspring rats sensitized against OVA, ${ }^{5}$ possibly by mechanisms involving inhibition of development and/or activity of the hypothalamic-pituitary-adrenal (HPA) axis in the fetuses or adult animals, ${ }^{17-20}$ as well as by a decrease in central corticosteroid receptors. ${ }^{21}$ Furthermore, a correlation between inflammatory (and/or immunological) hyperactivity and depression ${ }^{22}$ as consequence of HPA dysfunction has been reported in the endogenous depression. ${ }^{23}$ It is well known that 
corticosteroids and corticotrophin-releasing hormone are important modulators of the immune system, ${ }^{24}$ and impairment of the normal HPA functioning increases both the susceptibility to inflammatory processes and immunological responses. ${ }^{25}$ However, our present findings that behavioral depression failed to affect the counts of leukocytes in BAL fluid of sensitized rats do not support the concept that a HPA dysfunction contributes to allergic airway inflammatory responses in adult rats, since alterations on leukocyte migration pattern in BAL fluid would be expected. Accordingly, a previous study showed that inescapable footshocks in rats lead to an increase in plasma levels of adrenocorticotropic hormone and corticosterone, but this is not believed to modulate the effects of this stressor on pulmonary immune functions. ${ }^{6,7}$ Alveolar macrophages play an important role in the regulation of the local immune reactivity in the lung. Exposure of rats to inescapable footshocks leads to a decreased nitric oxide production and an increased interleukin-1 $\beta$ production by the alveolar macrophages, ${ }^{6,7}$ an effect completely suppressed by blockade of the autonomic nervous system, particularly with $\beta$-adrenoceptor antagonists. We conclude that mechanisms diverse of HPA axis functioning must be involved in allergic asthma in adult depressed rats.

ACKNOWLEDGMENT. Marcos A. Varriano was supported by CNPq.

\section{References}

1. Kroegel C, Virchow JC, Luttmann W, Walker C, Warner JA. Pulmonary immune cells in health and disease: the eosinophil leucocyte. Eur Resp J 1994; 7: 519-543.

2. Busse WW, Sedgwick JB. Eosinophils in asthma. Ann Allergy 1992; 68: 286-290.

3. Vianna EO, Garcia-Leme J. Allergen-induced airway inflammation in rats Role of insulin. Am J Resp Crit Care Med 1995; 151: 809-814.

4. Ferreira HHA, Bevilacqua E, Gagioti SM, Zanardo RCO, Teixeira CE, Sannomiya P, Antunes E, De Nucci G. Nitric oxide modulates eosinophil infiltration in antigen-induced airway inflammation in rats. Eur $J$ Pharmacol 1998; 358: 253-259.

5. Nogueira PJ, Ferreira HH, Antunes E, Teixeira NA. Chronic mild prenatal stress exacerbates the allergen-induced airway inflammation in rats. Med Inflamm 1999; 8: 119-122.

6. Persoons JH, Schornagel K, Breve J, Berkenbosch F, Kraal G. Acute stress affects cytokines and nitric oxide production by alveolar macrophages differently. Am J Respir Crit Care Med 1995; 152: 619-624.
7. Persoons JH, Moes NM, Broug-Holub E, Schornagel K, Tilders FJ, Kraal G. Acute and long-term effects of stressors on pulmonary immune functions. Am J Respir Cell Mol Biol 1997; 17: 3-8.

8. Broug-Holub E, Persoons JH, Schornagel K, Mastbergen SC, Kraal G Effects of stress on alveolar macrophages: a role for the sympathetic nervous system. Am J Respir Cell Mol Biol 1998; 19: 842-848.

9. Wamboldt FS, Rasanen M, Koskenvuo M, Romanov K, Varjonen J, Kaprio J. Familial association between allergic disorders and depression in adult Finnish twins. Am J Med Genet 2000; 96: 146-153.

10. Ritz T, Steptoe A. Emotion and pulmonary function in asthma: reactivity in the field and relationship with laboratory induction of emotion. Psychomos Med 2000; 62: 808-815.

11. O'Connor TM, O'Halloran DJ, Shanahan F. The stress response and the hypothalame-pituitary-adrenal axis: from molecule to melancholie. $Q M J$ 2000; 93: 323-333.

12. Maier SF. Learned helplessness and animal models of depression. Progr Neuropsychopharmacol Biol Psych 1984; 8: 435-446.

13. Hermini AH, Teixeira NA, Mendes VE, Pereira DG. Development of a software to control depression experiments through the 'learned helplessness'. Phys Med Biol 1994; 39: 430.

14. Secoli S, Teixeira NA. Chronic prenatal stress affects development and behavioral depression in rats. Stress 1998; 2: 273-280.

15. Barnes PJ. Our changing understanding of asthma. Respir Med 1989; 83S: $17-23$.

16. Teixeira MM, Williams TJ, Hellewell PG. Mechanisms and pharmacological manipulation of eosinophil accumulation in vivo. Trends Pharmacol Sci 1995; 16: 418-423.

17. Ward IL, Weiz J. Differential effects of maternal stress on circulating levels of corticosterone, progestone and testosterone in male and female rat fetuses and their mothers. Endocrinology 1984; 114: 1635-1644.

18. Weinstock M, Matlina E, Maos GI, Rosen H, McEwen B. Prenatal stress selectively alters the reactivity of the hypothalamic-pituitary-adrenal system in the female rats. Brain Res 1992; 595: 195-198.

19. Fameli M, Kitraki E, Stylianopoulou F. Efects of hyperactivity of the maternal hypothalamic-pituitary-adrenal (HPA) axis during pregnancy on these development of the HPA axis and brain monoamines of the offspring. Int J Dev Neurosci 1994; 12: 651-659.

20. MacCornick CM, Smythe JW, Sharma S, Mcaney MJ. Sex-specific effects of prenatal stress on hypothalamic-pituitary-adrenal responses to stress and brain glucocorticoid receptor density in adult rats. Dev Brain Res 1995; 84: 55-61.

21. Maccari S, Piazza PV, Kabbay M, Barbazangs A, Simon H, Le Moal M. Adoption reverses the long-term impairment in glucocorticoid feedback induced by prenatal stress. J Neurosci $1995 ; 15$ : 110-116.

22. Connor TJ, Leonard BE. Depression, stress and immunological activation: the role of cytokines in depressive disorders. Life Sci 1998; 62 583-606.

23. Gold PW, Goodwin FK, Chrousos GP. Clinical and biochemical manifestation of depression: relation to the neurobiology of stress. New Engl J Med 1988; 319: 348-420.

24. McEwin B, Biron C, Brunson K, Builock K, Chambers W, Dhabhar F, Goldfarbs R, Kitson R, Miller A, Spencer R, Weiss J. The role of adrenocorticoids as modulators of immune function in health and disease: neural, endocrine and immune interaction. Brain Res Rev 1997; 23: $79-99$.

25. Steinberg EM, Licino J. Overview of neuroimmune stress interactions implications for susceptibility to inflammatory disease. Stress basic mechanisms and clinical implications. Ann NY Acad Sci 1995; 771: 364-371.

Received 15 May 2001;

Accepted 13 June 2001 


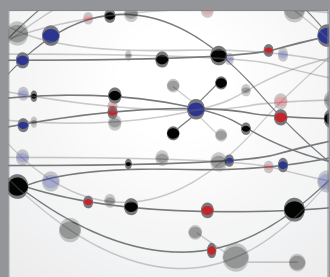

The Scientific World Journal
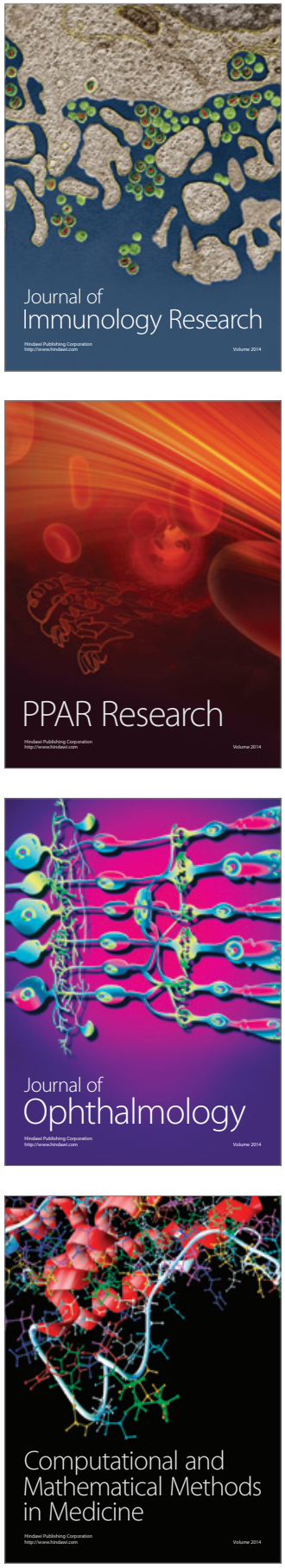

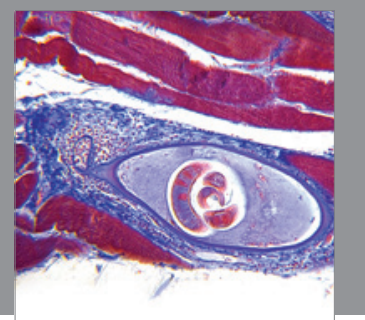

Gastroenterology

Research and Practice
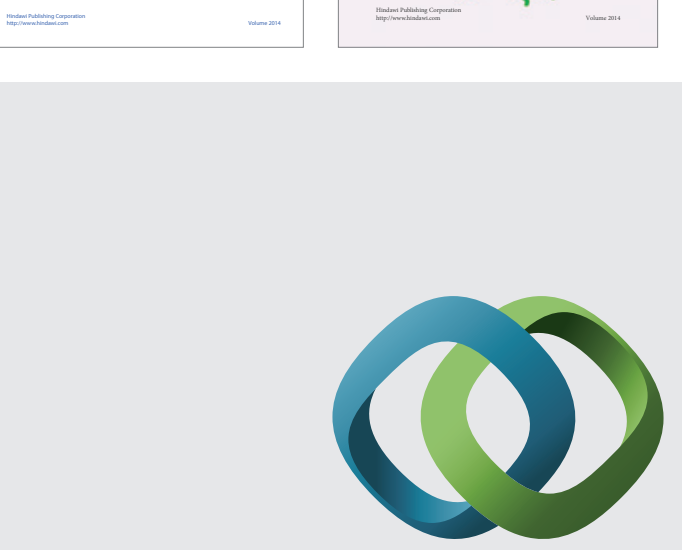

\section{Hindawi}

Submit your manuscripts at

http://www.hindawi.com
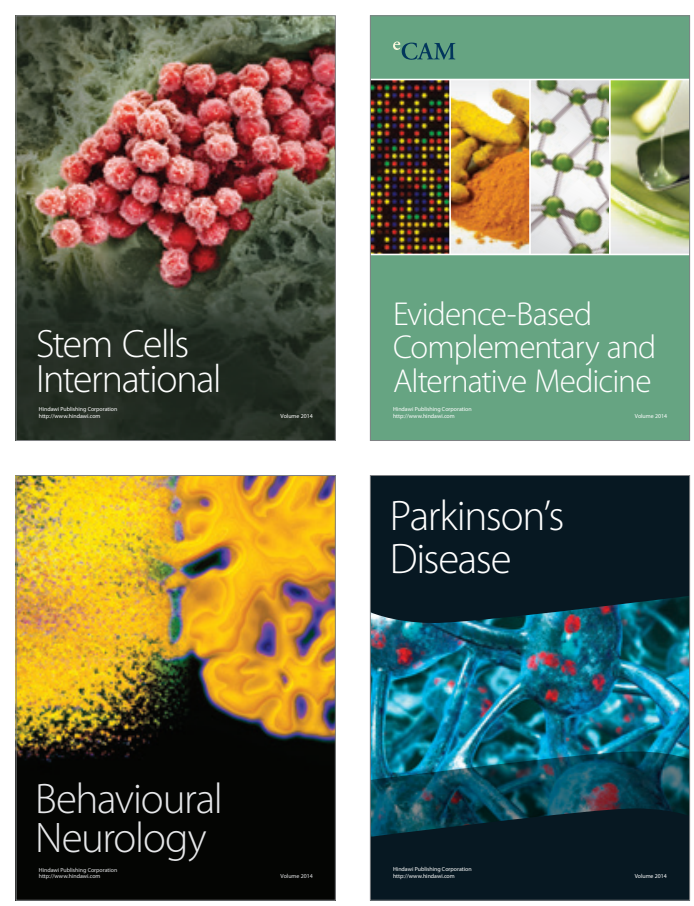

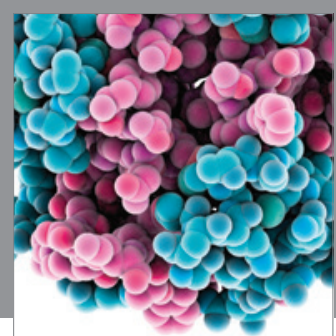

Journal of
Diabetes Research

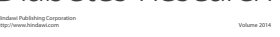

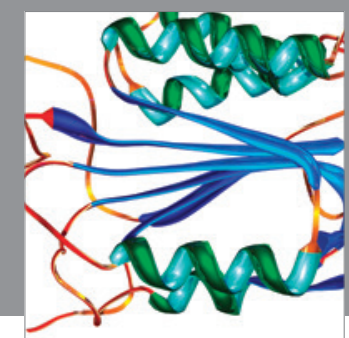

Disease Markers
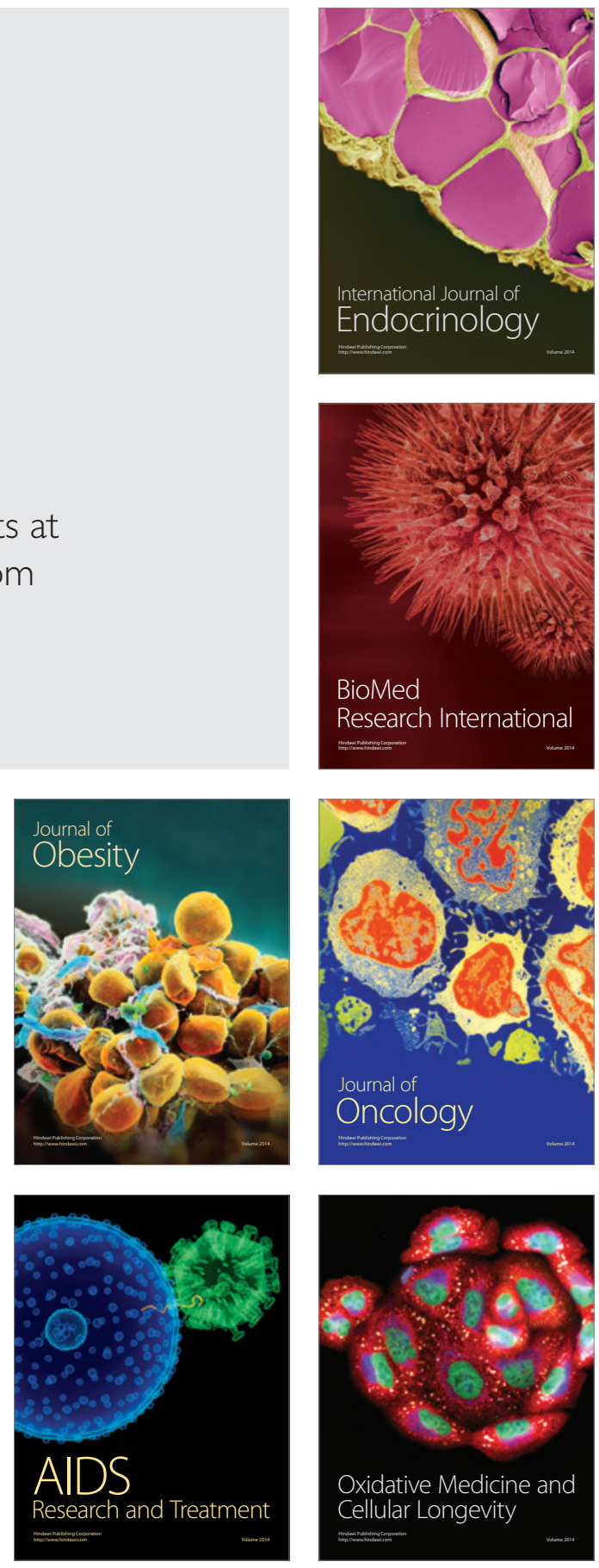